\title{
A non-equilibrium approach to modelling the weathering of stored Liquefied Natural Gas (LNG)
}

\author{
Calogero Migliore ${ }^{1,2}$, Amin Salehi $^{1}$, Velisa Vesovic ${ }^{1, *}$
}

${ }^{1}$ Department of Earth Science and Engineering, Imperial College London, London SW7 2AZ, United Kingdom

${ }^{2}$ Repsol, S. A., calle de Méndez Álvaro, 44, 28045, Madrid, Spain 


\begin{abstract}
A model is proposed to predict the weathering of LNG stored in containment tanks. It dispenses with a standard approximation where the temperature of the generated vapour within the tank is assumed to be the same as that of the stored LNG. Instead, it treats the heat influx from the surroundings into the vapour and liquid phases separately and allows for the heat transfer between the two phases. The model was validated only by comparing with the compositional data, as no reliable measurements of vapour temperature are available.
\end{abstract}

The simulation results indicate that the temperature of the vapour phase will be higher than that of the LNG, by approximately $8{ }^{\circ} \mathrm{C}$ over a period of one year, providing the heat transfer from the vapour is by conduction only; thus supporting circumstantial industrial findings. The effect on the Boil-off Gas (BOG) is considerable and the results indicate that the BOG rate will decrease by as much as $25 \%$ for particular scenarios. This has important consequences for weathering models used in industry, which currently assume isothermal conditions within the containment tanks.

In the initial stages of weathering, the nitrogen content of LNG will have a marked effect on the rate of BOG generation. The lowest BOG rate is observed when the LNG contains approximately 1.4$1.5 \%$ of nitrogen.

Keywords: $\quad$ LNG; Modelling; Boil-off Gas; Weathering; Vaporization 


\section{Introduction}

Natural gas is seen by many as an important energy resource in the $21^{\text {st }}$ century [1]. It is increasingly being utilised for power generation, and is already extensively used for industrial and household consumption, as well as for the production of advanced petrochemical derivatives. Its current global consumption is $3.5 \mathrm{Tm}^{3} / \mathrm{a}$ [2], which represents around a fifth of total energy usage, with forecasts indicating that the demand by 2035 is expected to be 50\% higher than today [1] Transportation is a major aspect of the natural gas supply chain [3], that ensures a stable and reliable link between the producers and end-users. Currently there exist two types of supply chains in the transportation of natural gas. One involves a conventional arrangement in which natural gas is transmitted all the way from the field to the consumer facility in high pressure pipelines. The other involves the liquefaction of the gas to form liquefied natural gas (LNG), its transportation in bulk carriers, regasification at the point of delivery and transportation to the final users also through high pressure pipelines. The choice of which supply chain to use depends primarily on the distance, but also on the location of the natural gas field and issues concerning the security of supply. An increasing number of producers and countries are choosing the LNG route [4]. The projected figures show that the LNG market is preparing for a significant growth with a number of new projects adding $0.62 \mathrm{Gm}^{3} / \mathrm{d}$ of capacity $\left(22 \mathrm{Bcf} / \mathrm{d}^{1}\right)$ by 2020 [4]. Overall, the LNG supply is expected to grow by $1.36 \mathrm{Gm}^{3} / \mathrm{d}(48 \mathrm{Bcf} / \mathrm{d}$ ) by 2035, with Australia and the US each contributing around a third of that increase. African LNG supply, led by East Africa, is also projected to increase significantly, adding around $0.34 \mathrm{Gm}^{3} / \mathrm{d}$ of capacity. Qatar, which has the largest market share today, is to be overtaken by Australia (24\% share of the market by 2035 ), Africa (21\%), and the US (18\%) by 2035 . Asian market, the largest destination for LNG, will represent above $70 \%$ of the global LNG demand by 2035, with China becoming the second largest LNG importer with 0.34 $\mathrm{Gm}^{3} / \mathrm{d}(12 \mathrm{Bcf} / \mathrm{d})$, just behind Japan with $0.37 \mathrm{Gm} / \mathrm{d}(13 \mathrm{Bcf} / \mathrm{d})$. Europe's share of global LNG imports is predicted to rise from $16 \%$ to $19 \%$ between 2013 and 2035 , with an additional 0.28 $\mathrm{Gm}^{3} / \mathrm{d}(10 \mathrm{Bcf} / \mathrm{d})$ of LNG consumption [4]. The increase in demand translates to increasing trade in LNG. Gas supplied via LNG is growing by $4.3 \%$ per annum, more than twice as fast as total trade. As a result, it is expected that LNG will overtake the pipeline natural gas as the dominant form of traded gas by 2035 [4]. Not all increase in demand can be attributed to economic and security of supply issues; LNG usage is also expanding rapidly and a number of industrial sectors are also utilizing it in its own right, without regasification to natural gas. For instance, it is increasingly being used as fuel in marine transport [5] and in heavy-duty road vehicles [6].

\footnotetext{
${ }^{1} \mathrm{Bcf} / \mathrm{d}$ stands for billion cubic feet per day and is equivalent to $10^{9} \mathrm{ft}^{3} / \mathrm{d}$.
} 
Production of LNG involves cooling the treated natural gas to approximately $-160{ }^{\circ} \mathrm{C}$ at atmospheric pressure. At these conditions natural gas occupies $1 / 600^{\text {th }}$ of its standard volume resulting in high energy content per unit volume, which has important implications for transportation. The LNG is transported by special marine carriers from the production facilities to the regasification terminals, where it is stored in highly insulated storage tanks at pressures slightly above atmospheric and temperatures corresponding to its boiling temperature $\left(\sim-160^{\circ} \mathrm{C}\right)$ [3]. Due to the heat ingress into the storage tank from the surroundings some of the LNG will vaporize, resulting in an increase in the overall tank pressure. In order to avoid over-pressurization of the tank the boil-off gas (BOG) produced is continuously removed by BOG compressors at the rate at which the LNG vaporizes, thus maintaining constant pressure inside the tank.

Commercial LNG is a methane-rich mixture that also contains nitrogen, ethane, propane and traces of heavier alkanes. As LNG evaporates, the more volatile components (methane and nitrogen) will vaporize preferentially and the remaining LNG becomes richer in the heavier components (ethane, propane, etc.). The change in LNG composition will influence not only its thermodynamic properties, in particular the boiling temperature and latent heat, but also its heating value which determines its regulatory suitability for export to the grid. The process of preferential vaporization of stored LNG is known in the industry as "weathering", and can be summarized as the progressive alteration of thermophysical properties of stored LNG through vaporization, due to the heat ingress from the surroundings.

Weathering prediction of stored LNG is of particular significance for the LNG industry, especially in LNG shipping and in the operation of regasification facilities. In particular, it helps to: (i) anticipate the allocation of LNG cargoes and to set-up the operation of the receiving terminal in advance; (ii) plan operating procedures to ensure the suitability of the delivered natural gas in terms of its properties and heating value; (iii) evaluate the compatibility of the stored LNG with respect to the grid, especially in long term LNG storage; (iv) anticipate the consequence of loading a new batch of LNG, which will by necessity be lighter and cooler in order to prevent possible undesirable events involving stratification, sudden vapour release and rollover.

Study of the LNG weathering is closely linked with industry developments and requirements. Early research focussed on establishing BOG rates by modelling pure methane evaporation [7,8], and providing experimental data [9]. More recent studies have focussed on the development of physically realistic models to represent weathering during marine transportation [10-12] and in storage tanks [13-16]. Although the models have become more sophisticated, they all invoke an assumption that the stored LNG is in thermal equilibrium with a vapour blanket above it. Recent industrial evidence shows that this is not the case and that the vapour temperature is higher than 
the LNG temperature [17] although the two are in contact. As the heat enters the storage tank it heats the vapour phase, increasing its temperature, while concurrently causing the evaporation of the LNG, which remains at its boiling temperature throughout the process. If the process of heat transfer from the vapour to the liquid is slow a temperature difference between the two phases will be established.

In this study, we examine the consequences of the two phases not being in thermal equilibrium and present a new weathering model in which the heat influx into the vapour and liquid sections of the storage tank are treated separately. The model takes into account that the vapour phase, being at a higher temperature than the LNG, will act as an additional heat source giving rise to further weathering. The proposed modelling approach is analogous to that used for the modelling of blowdown [18-20], where the heat influx into the vapour and liquid sections of the de-pressurising vessel is treated separately. The developed models accurately predicted the individual temperature evolution of the vapour and liquid phases during the depressurization process, which would not be possible if the two phases were assumed to be in thermodynamic equilibrium. More importantly, from an engineering perspective, the assumption of thermal equilibrium led to predicting unrealistically low fluid and vessel wall temperatures, resulting in too conservative designs and implementation of larger safety margins than was necessary.

In section 2 we start by describing the developed model and provide the relevant equations. In section 3 , the methodology for the calculation is presented together with the results of the validation tests. Section 4 contains the results and discussion of weathering process for different scenarios. The analysis includes the examination of different assumptions concerning the heat transfer mechanism between the vapour and the liquid phase. Finally, a summary and conclusions of the results are given in Section 5 . 


\section{Model development}

In this section we present a new model for the LNG weathering in a closed vessel, derived without invoking a standard assumption that the LNG vapour is at the same temperature as that of the weathering liquid. We take as a starting point our previous work [16] where an assumption of thermal equilibrium between the vapour and liquid phase was made. To avoid unnecessary repetition, we only present the working equations relevant to the new model and refer the reader to Ref. [16] for a more detailed description of the overall model.

\subsection{Model implementation}

LNG is usually stored in well-insulated vessels at slight over-pressure, at roughly its boiling temperature. The heat ingress from the surroundings causes the preferential evaporation of lighter components, with the produced vapour being removed as boiled-off gas (BOG) to control the tank pressure. Although the developed model is generic and can be adapted to any storage vessel, we focused in this work on modelling the weathering in a typical above-ground storage tank [3], schematically shown in Figure 1, used in industry to store received LNG.

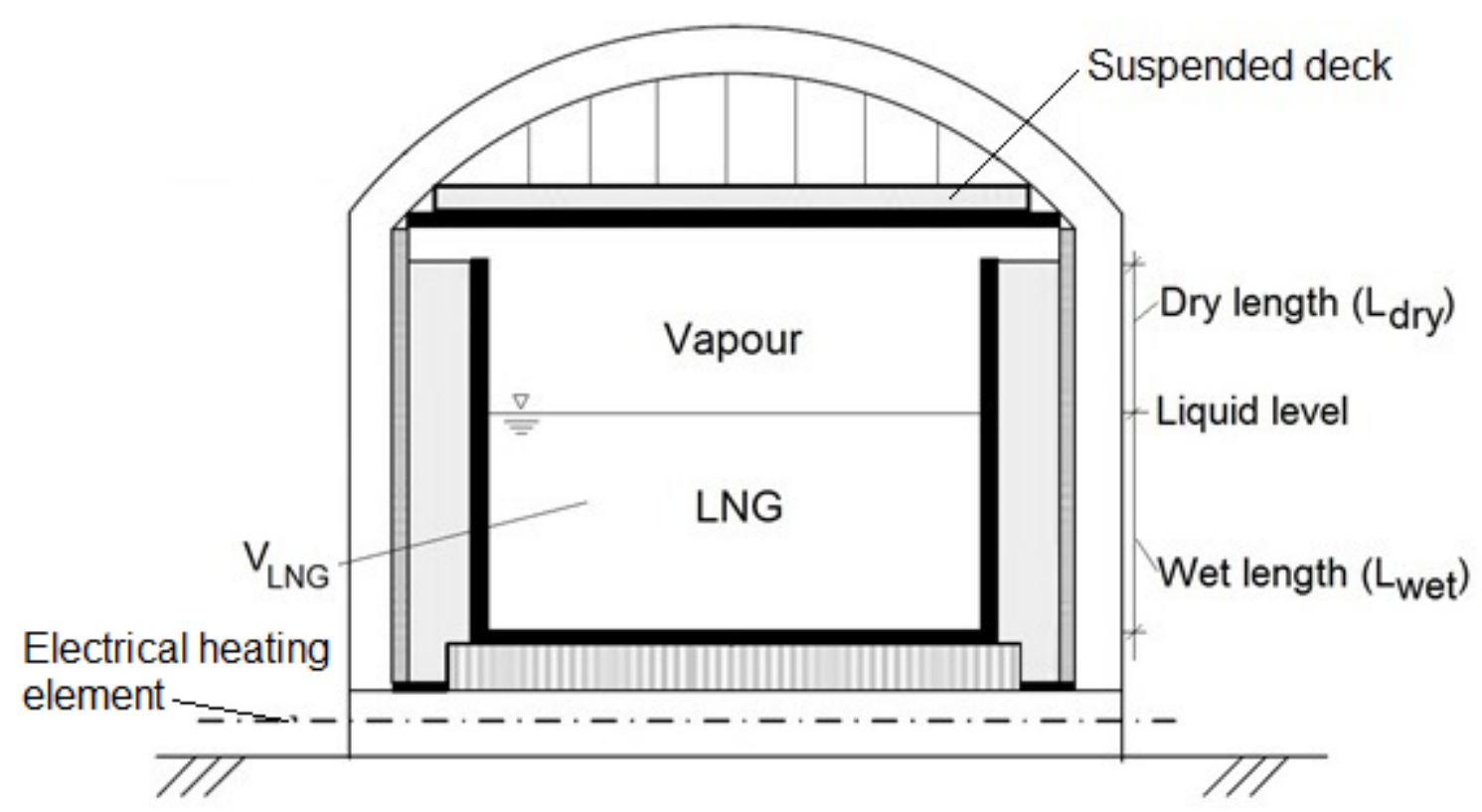

Figure 1 Schematic of LNG storage tank 
In this configuration the heat from the surroundings can enter the tank through the lateral walls, the roof and the bottom slab. In industrial storage tanks, the bottom slab is maintained at constant temperature using an electrical heating element and temperature sensors, to prevent ground freezing. Thus, in the developed model the heat transfer through the bottom of the tank was assumed to be constant and independent of the temperature of the surroundings. Furthermore, in most industrial storage tanks the inner face of the concrete roof is not directly exposed to the vapour phase that is in contact with the LNG, as the suspended deck and the deck insulation act as a thermal barrier, (see Figure 1). Thus the developed model only considers the heat ingress through lateral walls and the bottom slab and does not account for the heat ingress from the tank roof. However, in a different tank set up the roof contribution can easily be added in.

Figure 2 illustrates the schematic showing the heat exchange between the different phases of the system and the surroundings. We distinguish the heat contributions to the vapour, $Q_{V i n}$, and liquid, $Q_{\text {Lin }}$, phases from the surroundings through the lateral wall separately from the heat contribution from the bottom slab, $Q_{\text {slab }}$. We note that the heat entering the liquid phase will primarily lead to weathering with slow increase in the boiling temperature, due to the change of LNG composition. In comparison, the heat entering the vapour phase leads to an increase in its temperature only. Hence, the vapour temperature $T_{\mathrm{v}}$ is always going to be equal or greater than the liquid temperature $T_{\mathrm{L}}$. As a consequence, the vapour will act as an additional heating surface, leading to heat transfer from the vapour phase to the liquid phase, $Q_{V L}$. 


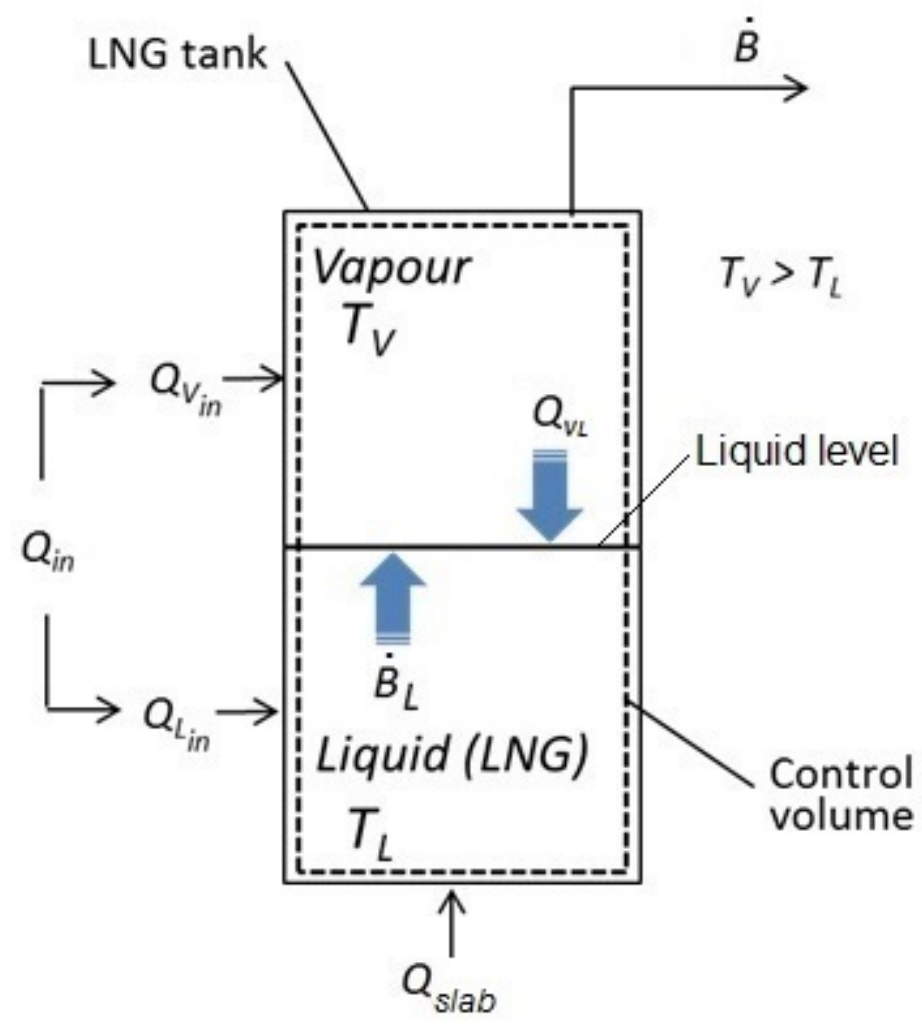

Figure 2 Schematic of the heat exchange between the surroundings, LNG and vapour

The quantities $\dot{B}$ and $\dot{B}_{L}$ represent the rate of vapour removal (BOG rate) and rate of vaporization, respectively. The rate of vaporization, $\dot{B}_{L}$, is defined as,

$$
-\dot{B_{L}} \equiv-\frac{d B_{L}}{d t}=\frac{d\left(\rho_{\mathrm{L}} V_{\mathrm{L}}\right)}{d t}
$$

while the mass balance over the whole system indicates that $\dot{B}$ is given by,

$$
-\dot{B} \equiv-\frac{d B}{d t}=\frac{d\left(\rho_{\mathrm{L}} V_{\mathrm{L}}\right)}{d t}+\frac{d\left(\rho_{\mathrm{V}} V_{\mathrm{V}}\right)}{d t}=-\dot{B_{L}}+\frac{d\left(\rho_{\mathrm{V}} V_{\mathrm{V}}\right)}{d t}
$$

where $\rho$ is the molar density and the subscripts $V$ and $L$ indicate vapour and liquid, respectively. The quantity $V$ is the volume of the storage tank occupied by both the liquid, $V_{L}$, and vapour, $V_{V}$. Taking into account that the volume of the tank is constant,

$$
\frac{d V_{\mathrm{L}}}{d t}=-\frac{d V_{\mathrm{V}}}{d t}
$$

the term $d V_{\mathrm{V}} / d t$ represents the volumetric rate of LNG evaporation. 
The energy balance leads to a coupled set of differential equations that govern the behaviour of the system,

$$
\begin{gathered}
Q_{V, \text { in }}-Q_{V L}=\frac{d H_{\mathrm{V}}}{d t}+\dot{B} h_{\mathrm{V}}\left(T_{V}\right)-\dot{B_{L}} h_{\mathrm{V}}\left(T_{L}\right) \\
Q_{L, \text { in }}+Q_{V L}+Q_{s l a b}=\frac{d H_{\mathrm{L}}}{d t}+\dot{B}_{L} h_{\mathrm{V}}\left(T_{L}\right),
\end{gathered}
$$

where $H$ and $h$ are the enthalpy and molar enthalpy, respectively. The right-hand side of Eqs. (4-5) contain only thermodynamic quantities and their evolution with time, and can in principle be obtained from an appropriate thermodynamic model. For this purpose, we have used the same thermodynamic model as in our previous work [16] and the reader is referred to it for a complete description. The thermodynamic model is based on the Peng-Robinson Equation of State (PREOS) and makes use of standard van der Waals mixing rules with the recommended interaction parameters. The composition evolution of the LNG and the vapour phase, during the weathering process, was obtained by solving the standard Rachford-Rice equation for the vapour-liquid equilibrium where the equilibrium constants were obtained as the ratios of the fugacity coefficients [21]. The fugacity coefficients, the molar enthalpies and the density of the vapour phase were obtained by means of the PR-EOS, as described in Migliore et al. [16]. The density of the liquid phase can be obtained in a similar manner, but it is known that PR-EOS will underestimate the liquid density, unless the volume shift is introduced. Hence, in line with previous work we have opted to use the revised Klosek-McKinley method as it has been specifically developed to estimate the density of LNG [22].

The heat ingress through the tank walls depends on the temperature of the surrounding air and the liquid level in the tank. As the heat transfer from the surrounding air to the inside of the tank is by a combination of conduction and convection, one can write the expressions for $Q_{\text {in }}$ as,

$$
\begin{gathered}
Q_{V, \text { in }}=U_{\mathrm{dry}} A_{\mathrm{dry}}\left(T_{\mathrm{air}}-T_{V}\right) \\
Q_{L, \text { in }}=U_{\mathrm{wet}} A_{\mathrm{wet}}\left(T_{\mathrm{air}}-T_{L}\right),
\end{gathered}
$$

where $U$ is the overall heat transfer coefficient, $A$ is the contact area and subscripts wet and dry refer to the sections of the tank filled with liquid and vapour, respectively. The overall heat transfer coefficient was estimated by considering the heat transfer by convection from the surrounding air 
to the outside wall, by conduction through the three layered insulated wall and by internal convection to the inside of the storage tank. The full details are given in our previous work [16].

Equations (1-7) constitute the working model. Before they can be used to calculate the LNG weathering they have to be supplemented by the model of heat transfer between the vapour and liquid phase, $\mathrm{Q}_{\mathrm{VL}}$.

\subsection{Heat exchange between the vapour and liquid}

The LNG stored in the industrial storage tanks, illustrated in Fig. 1, is always at or very near its boiling temperature. Although the boiling temperature increases with time, as a result of the weathering process that leads to LNG getting richer in heavier components, the variation is very slow and slight. Marked differences are only observed at the very end of the weathering process [23]. It can be thus assumed that LNG, in contact with the vapour at higher temperature, acts as a constant temperature heat sink, at least over short time intervals. The heat transfer between the two phases can occur by conduction and convection. In order to understand the dynamics of the heat exchange between the vapour and the liquid we have examined two limiting scenarios. In the first, we assume that the heat transfer from the vapour is by conduction only, while in the second we assume a fully convective heat transfer. For convenience we will further refer to these as the conduction model and the convection model.

\subsubsection{Heat exchange by conduction}

We assume that the heat transfer takes place in a direction perpendicular to the liquid surface, denoted $z$ in this work, and that the edge effects are negligible, due to the size of the tank. The latter is a reasonable assumption as long as the diameter of the tank is larger than $0.5 \mathrm{~m}$ [24]. Hence, the heat transfer can be approximated by one-dimensional heat conduction equation of the form,

$$
\frac{\partial T_{\mathrm{V}}}{\partial t}=\alpha \frac{\partial^{2} T_{\mathrm{V}}}{\partial z^{2}}
$$

with the following initial and boundary conditions,

$$
\begin{array}{ll}
t=0 & T_{\mathrm{V}}=T_{\mathrm{V}_{0}} \\
z=0 & T_{\mathrm{V}}=T_{\mathrm{L}} \\
z=h & T_{\mathrm{V}}=T_{\mathrm{V}_{0}} .
\end{array}
$$


where $z=h$ is the height of the tank space filled with vapour, measured from the LNG surface $(z=0)$, $T_{V_{0}}$ is the initial temperature of the vapour and $\alpha$ is the vapour thermal diffusivity. If we assume a standard solution valid for the semi-infinite space $(0 \geq z \geq \infty)$, we obtain the following temperature profile within the vapour phase [25],

$$
T_{\mathrm{V}}=\left(T_{\mathrm{V}_{\mathrm{o}}}-T_{\mathrm{L}}\right) \operatorname{erf}\left(\frac{z}{2 \sqrt{\alpha t}}\right)+T_{\mathrm{L}}
$$

For the time interval of interest to this work the temperature drop in the vapour phase extends only over the values of $z$ that are at least one order of magnitude smaller than the height of the vapour space, $h$, thus justifying the use of the semi-infinite solution, Eq. (9).

During the particular time interval, corresponding to a time step in our simulations, the temperature profile will be established within the vapour phase due to the cooling effect of the LNG. The resulting average vapour temperature, $T_{\text {vavg }}$, that the vapour will attain at the end of a time step is given by,

$$
T_{\mathrm{V} a v g} \equiv T_{\mathrm{V}, \mathrm{t}+\Delta \mathrm{t}}=\int_{0}^{h} T_{\mathrm{V}} \cdot d z
$$

Consequently the amount of heat transferred from the vapour to the liquid, $Q_{V L}$, within the time step is given by,

$$
Q_{V L}=n_{V} C_{p, V}\left(T_{V, i}-T_{V, t+\Delta t}\right)
$$

where $n_{\vee}$ is the number of moles in the vapour phase, $C_{p}^{v}$ is the vapour molar heat capacity at constant pressure, $T_{V, t+\Delta t}$ is the final vapour temperature and $T_{V, i}$ is the initial vapour temperature following the ingress of heat during the time step $\Delta t$.

\subsubsection{Heat exchange by natural convection}

For convective heat transfer the amount of heat transferred from the vapour to the liquid $Q_{V L}$, is given by,

$$
Q_{V L}=h A\left(T_{V}-T_{L}\right)
$$

where $h$ is the heat transfer coefficient and $A$ is the vapour-liquid contact area. The heat transfer coefficient is traditionally obtained from empirical correlations that depend on the geometry and orientation of the contact area and the fluid phases present and are expressed in terms of 
dimensionless numbers. In this work we made use of the Kozanoglu and Rubio [26] empirical relationship, which is valid for a cooling horizontal plate facing upwards and is independent of the nature of the flow regime in the convecting phase,

$$
N u=0.116 R a^{0.32}
$$

where Nusselt $(\mathrm{Nu})$ and Rayleigh $(\mathrm{Ra})$ numbers are given by,

$$
\begin{gathered}
N u=\frac{h L}{k} \\
R a=\frac{g \beta \rho^{2}\left(T_{V}-T_{L}\right) L^{3} C_{p, V}}{\mu k} .
\end{gathered}
$$

The quantity $\beta$ is the thermal expansion coefficient, $\mu$ is the viscosity and $k$ is the thermal conductivity of the vapour phase, while $g$ is the gravitational constant. The characteristic length, $L$, which defines the convective domain, is notoriously difficult to estimate and a number of workers ( see [27] and references there in) have proposed different relationship whose validity tends to be limited by geometric and convective flow considerations. In this work for consistency we employ the empirical relationship proposed by Kozanoglu and Rubio [26],

$$
L=0.00082 R a^{0.31}
$$

which can be made explicit by combining with Eq. (15)

$$
L=8.1588 \times 10^{-45}\left(\frac{g \beta \rho^{2}\left(T_{V}-T_{L}\right) C_{p, V}}{\mu k}\right)^{4.4286} .
$$

Once we have estimated the amount of heat transferred from the vapour to the liquid $Q_{V L}$, within the time step, we can calculate the vapour temperature at the end of the time step through simple heat balance as,

$$
T_{V, t+\Delta t}=T_{V, t}+\frac{Q_{i n, V}-Q_{V L}}{n_{V} C_{p, V}}
$$


We initiate the model by defining the storage tank dimensions, operating pressure, initial inventory, initial LNG composition and ambient temperature. We then solve Eqs. (1-2) and (4-5) using finite difference method by specifying a time step. At each time step we first evaluate the amount of heat that has entered the liquid side of the storage tank, by recourse to Eq. (7), and by knowing how

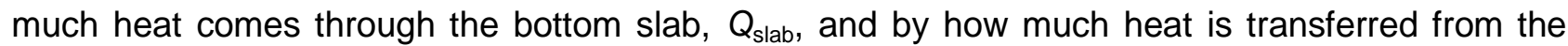
vapour, $Q_{V L}$, based on the calculations performed in the previous time step. We follow the procedure adopted for the isothermal model [16] and perform the VLE calculation to ascertain the composition and the amounts of two phases present at the end of a given time-step. Once the liquid side is solved, the calculation sequence proceeds to solving the vapour phase. We first evaluate the amount of heat that has entered the vapour side within the time step, by recourse to Eq. (4). For the conduction model we then estimate the new vapour temperature by solving the enthalpy balance around the vapour phase, taking into account the amount of vapour generated, $B_{\mathrm{L}}$. We then make use of Eqs. (9-10) to evaluate the temperature the vapour will attain following the cooling provided by the LNG and Eq. (11) to estimate the amount of heat transferred from the vapour to the liquid phase. In the convection model we first estimate the heat transfer from the vapour to the liquid phase, $Q_{V L}$, by means of Eq. (12) and then evaluate the vapour temperature by recourse to Eq. (18).

Prior to commencing the simulations, convergence tests were performed to ascertain the optimal time step for the study. As the conduction case will lead to the highest increase in the vapour temperature, these results are used to illustrate the convergence of the solutions. Figures $3 a$ and $3 \mathrm{~b}$ show the variation of vapour temperature and BOG mass rate, respectively over a period of 12months as a function of time step for a $165,000 \mathrm{~m}^{3}$ storage tank at constant pressure of $116.3 \mathrm{kPa}$, and initial LNG inventory of $160,000 \mathrm{~m}^{3}$ for LNG mixture classified previously as LNG with $\mathrm{N}_{2}$ [16].
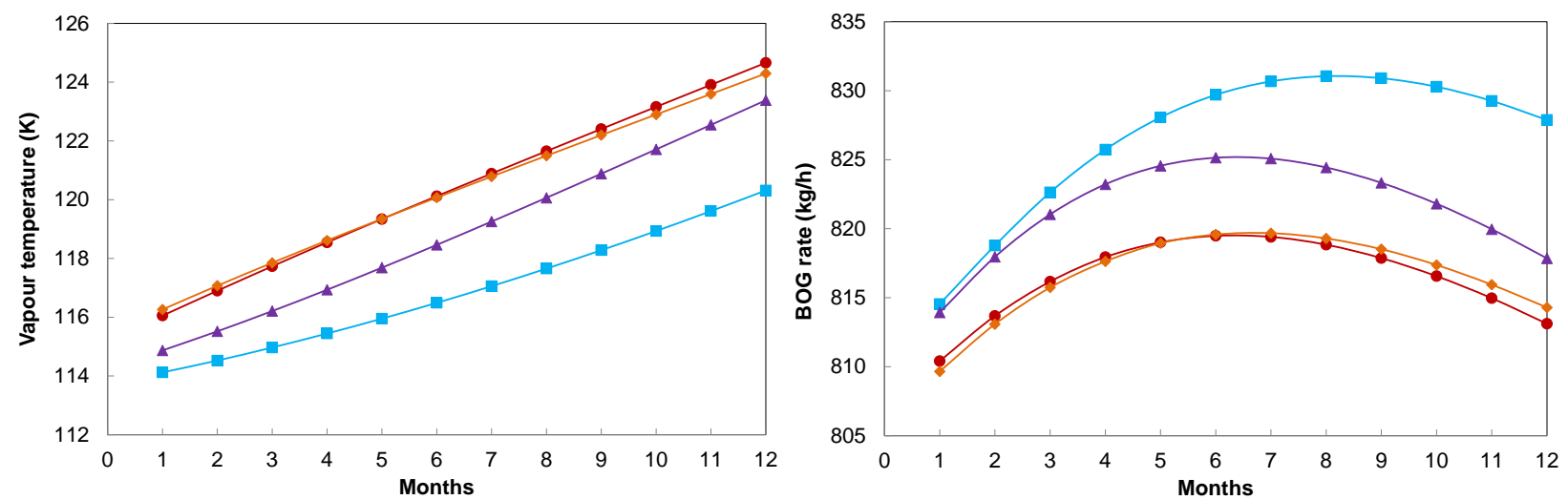

Figure 3 The evolution of the vapour temperature, $T_{\mathrm{v}}$ and BOG rate as a function of time for different time steps: (- 12 hours; - - 1 day; - $\mathbf{A}-1$ week; - 1 month) 
The convergence tests indicate that time steps as large as 1 day are suitable for the weathering simulations as the numerical errors observed in estimating the vapour temperature, $T_{V}$, and BOG rate are within $0.3 \%$ and $0.2 \%$, respectively. Nevertheless, as the computational times to perform the simulations are of the order of minutes, all the simulations were performed with a time step of 1 hour, thus ensuring more than adequate convergence. The fact that it is possible to simulate the weathering process with the size of the time step of 1 day further confirms that thermophysical changes that occur during weathering are slow and that the system can be taken to be in a quasi steady-state over the periods of time of less than a day.

The lack of verifiable and reliable experimental data on LNG weathering makes any model validation difficult. Following the procedure we used in our previous work [16] we have compared the prediction of the current model with selected data obtained from historical cargo measurements, as reported by Miana et al. [11]. As measured data were obtained for LNG weathering during the marine transport, we have made use of constant BOR of $0.15 \%$ [16], quoted by Miana et al. and routinely used in the shipping industry, to adjust the overall heat transfer coefficient $U\left(U=\sim 0.36 \mathrm{~W} / \mathrm{m}^{2} / \mathrm{K}\right)$ in eq. (6-7). Hence, as discussed previously [16], the validation tests only the thermodynamic module and mass balance equations that we have implemented in our model. Furthermore, the main new feature of the current model, the heat transfer between the vapour and the LNG is only implicitly tested as far as it influences the BOG rate and hence the dynamics of LNG enrichment. The agreement with measured data is excellent, if anything it is marginally better than that obtained with the isothermal model [16]. The current model reproduces the measured compositional data to better than 0.003 of mole fraction, the final volume to better than $0.3 \%$, while the predicted density and temperature are within $0.95 \%$ and $0.80 \%$ of the measured values.

\section{Results and discussion}

The conduction and convection models were run to assess the weathering behaviour of stored LNG on a long term basis (52 weeks) using the same standard 165,000 $\mathrm{m}^{3}$ containment tank as described in our previous work [16], assuming an outside temperature of $25^{\circ} \mathrm{C}$. The heat entering the tank was assumed to come through the bottom slab and through the lateral walls. Migliore et al. [16] in their study assume a heat ingress through the roof and thermal slab of $100 \mathrm{~kW}$. In this case the heat entering from the roof is omitted considering the barrier effect of the suspended deck as discussed earlier; for the thermal slab $60 \mathrm{~kW}$ heat input is assumed which is standard for an LNG tank of $165,000 \mathrm{~m}^{3}$ [17]. 
We have opted to perform the analysis considering an initial filling volume of $160,000 \mathrm{~m}^{3}$ using three commercial LNG mixtures as described in our previous work [16]. These are: (i) a 'light LNG' that primarily consists of methane with a small amount of ethane present; (ii) a 'heavy LNG' where the amount of methane is around 91.6\%; and (iii) 'LNG with $\mathrm{N}_{2}$ '. Table 1 summarizes the composition of the LNG mixtures used. We have simulated the weathering behaviour over a period of one year. Although this exceeds the storage time even in peak-shaving facilities, it is useful to establish emergence of trends.

Table 1. LNG compositions (mole fraction)

\begin{tabular}{cccc} 
Component & Light LNG & Heavy LNG & LNG with $\mathbf{N}_{\mathbf{2}}$ \\
\hline $\mathbf{C}_{\mathbf{1}}$ & 0.9613 & 0.9164 & $0.9307-0.9229$ \\
$\mathbf{C}_{\mathbf{2}}$ & 0.0340 & 0.0576 & $0.0661-0.0326$ \\
$\mathbf{C}_{\mathbf{3}}$ & 0.0039 & 0.0204 & $0.0006-0.0038$ \\
$\mathbf{i}-\mathbf{C}_{4}$ & 0.0004 & 0.0029 & $0.0000-0.0004$ \\
$\mathbf{n}-\mathbf{C}_{4}$ & 0.0003 & 0.0022 & $0.0000-0.0003$ \\
$\mathbf{i}_{\mathbf{4}} \mathbf{C}_{\mathbf{5}}$ & 0.0000 & 0.0002 & 0.0000 \\
$\mathbf{N}_{\mathbf{2}}$ & 0.0001 & 0.0003 & $0.0026-0.040$ \\
\hline $\boldsymbol{T}_{\text {boiling, }}{ }^{\circ} \mathbf{C}$ & -159.4 & -158.9 & $-159.9--169.9$ \\
\hline
\end{tabular}

\subsection{Light $L N G$}

During the period of a year the weathering of light LNG leads to enrichment of remaining LNG. However, due to the size of the standard storage tank the overall decrease of the LNG methane content is small, from $96.1 \%$ to $95.7 \%$; this results in only $0.1 \mathrm{~K}$ increase in the LNG boiling temperature, which can be thus assumed to remain constant at $113.8 \mathrm{~K}$ for the entire weathering duration. The temperature of the vapour above the LNG increases due to ingress of heat and Figure 4 illustrates the estimated increase in the vapour temperature as a function of time. We observe that the vapour temperature is strongly influenced by the heat transfer mechanism for cooling by LNG. If we assume that the cooling of the vapour occurs by conduction only, the vapour temperature increases by $7.6 \mathrm{~K}$ at the end of the weathering process. If the convection within the vapour phase materializes then the cooling is much more efficient and the temperature of the vapour phase will only increase by one degree. 


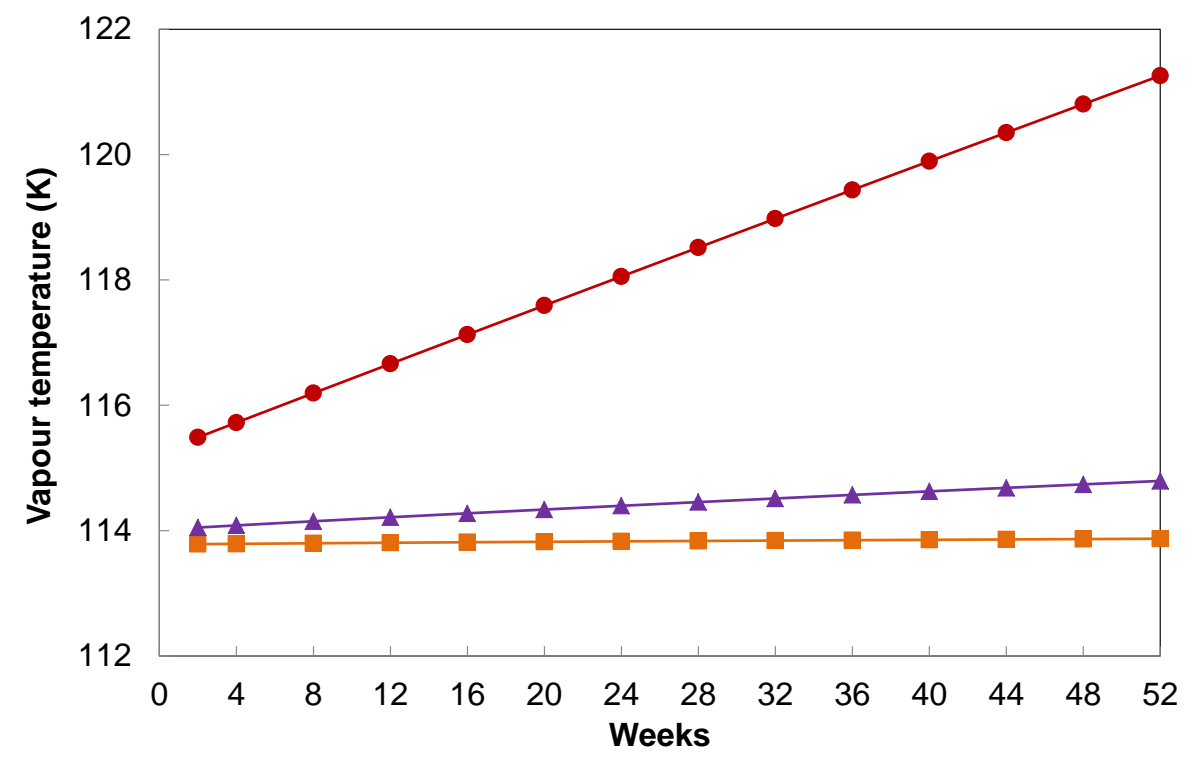

Figure 4 The variation of the Vapour Temperature during the weathering process conduction model; - $\boldsymbol{\Lambda}$ - convection model; - $-\mathbf{-}$ - isothermal model [16] )

Figure 5 illustrates the behaviour of BOG rate during the weathering period. One can observe that in contrast to the isothermal model, where the BOG generation rate hardly changes [16], for the conduction model BOG rate progressively decreases to $832 \mathrm{~kg} / \mathrm{h}$, corresponding to approximately a $3 \%$ drop. The BOG rate decrease is a result of progressive reduction of the wet heat transfer contact area as the LNG level drops, due to evaporation. The simulation indicates that on an annual basis the height of LNG in the tank decreases from $34.9 \mathrm{~m}$ to $31.1 \mathrm{~m}$, and as a consequence the amount of heat influx through the walls decreases by $11 \%$. Although the vapour temperature increases, the heat transfer from the vapour phase contributes approximately $4 \%$ to the overall heat transfer and is insufficient to keep the BOG rate constant.

In contrast if we examine the convective model we observe only a small decrease in the BOG ratio, as illustrated in Fig. 5. In this scenario very little heat is retained by the vapour, see Fig. 4, resulting in an efficient heat transfer from the vapour phase which is sufficient to replenish the decrease in heat influx through the walls into the liquid. 


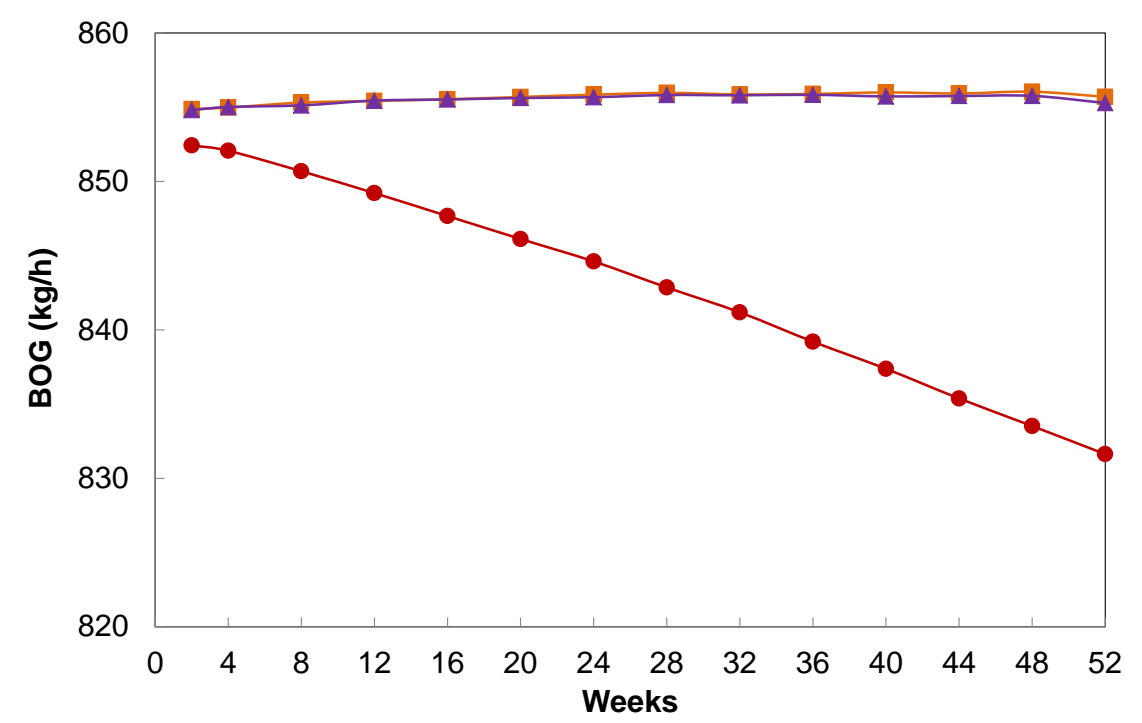

Figure 5 The variation of the BOG rate during the weathering process $(-\bullet-$ conduction model; - $\boldsymbol{\Lambda}$ - convection model; - $\square$ - isothermal model [16])

In the present economic climate a number of storage tanks are not operated at full capacity and in some cases less than half a tank is filled with LNG. This causes a subtle modification of the weathering dynamics which is not possible to account for when the isothermal model is employed. The effect is more prominent for the conduction case and we illustrate it by comparing the weathering behaviour of the tank filled initially with $80,000 \mathrm{~m}^{3}$ of LNG with the behaviour of an identical storage tank that has started with $160,000 \mathrm{~m}^{3}$ of LNG and has, through weathering, reached $80,000 \mathrm{~m}^{3}$ level. For convenience we will refer to the former as the half-filled tank, and to the latter as the half-empty tank. Figure 6 illustrates the behaviour of vapour temperature and the BOG rate in the first month of comparison. We observe that the half-filled tank needs approximately twenty days for its vapour temperature to reach that of the half-empty tank that has been weathered for some time. As a consequence the initial BOG rate of the half-filled tank is lower, as the influx of heat from the vapour phase is lower. At later stages the two BOG rates are approximately the same, the slight difference is due to the different levels of LNG present. The half-filled tank will contain, due to a lower initial BOG rate, more of LNG at any particular time and will consequently at later stages receive proportionally more heat through the walls than the halfempty tank. 

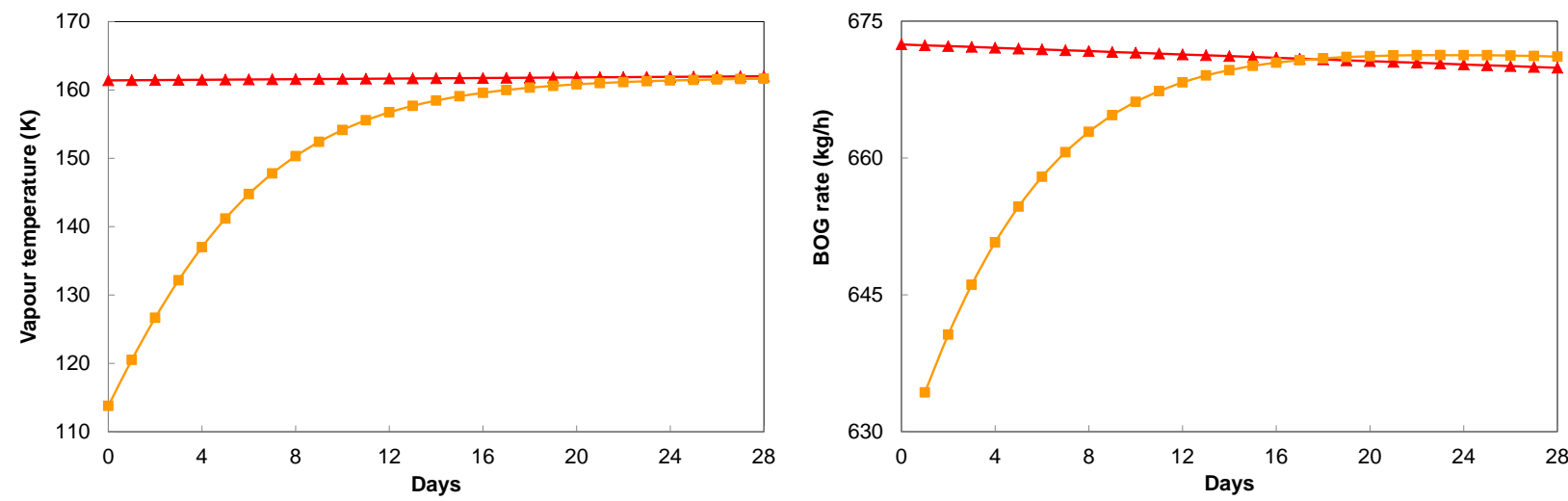

Figure 6 The evolution of the vapour temperature, $T_{\mathrm{v}}$ and BOG rate as a function of time, for two identical tanks both containing $80,000 \mathrm{~m}^{3}$ of LNG: $\left(-\Delta-\right.$ the tank has reached $80,000 \mathrm{~m}^{3}$ through weathering; - - the tank has been filled with $80,000 \mathrm{~m}^{3}$ of LNG )

Figure 7 illustrates the behaviour of the BOG rate as a function of the amount of LNG evaporated, defined as mole percentage of LNG vaporized with respect to the initial amount LNG present [16]. The convection model shows a BOG rate similar to that already reported for the isothermal case [16]. The BOG rate remains constant until approximately $85 \%$ of the original LNG has evaporated and is independent of the amount of LNG present. In the final stages of the evaporation, when the heat entering the tank through the bottom slab starts to dominate the heat influx and when the enrichment of LNG is high, the BOG rate drops substantially. A similar late stage drop in the BOG rate is observed for the isothermal model and as discussed previously [16], it is a direct consequence of the LNG enrichment which leads to an increase in both the boiling temperature and the indirect differential latent heat.

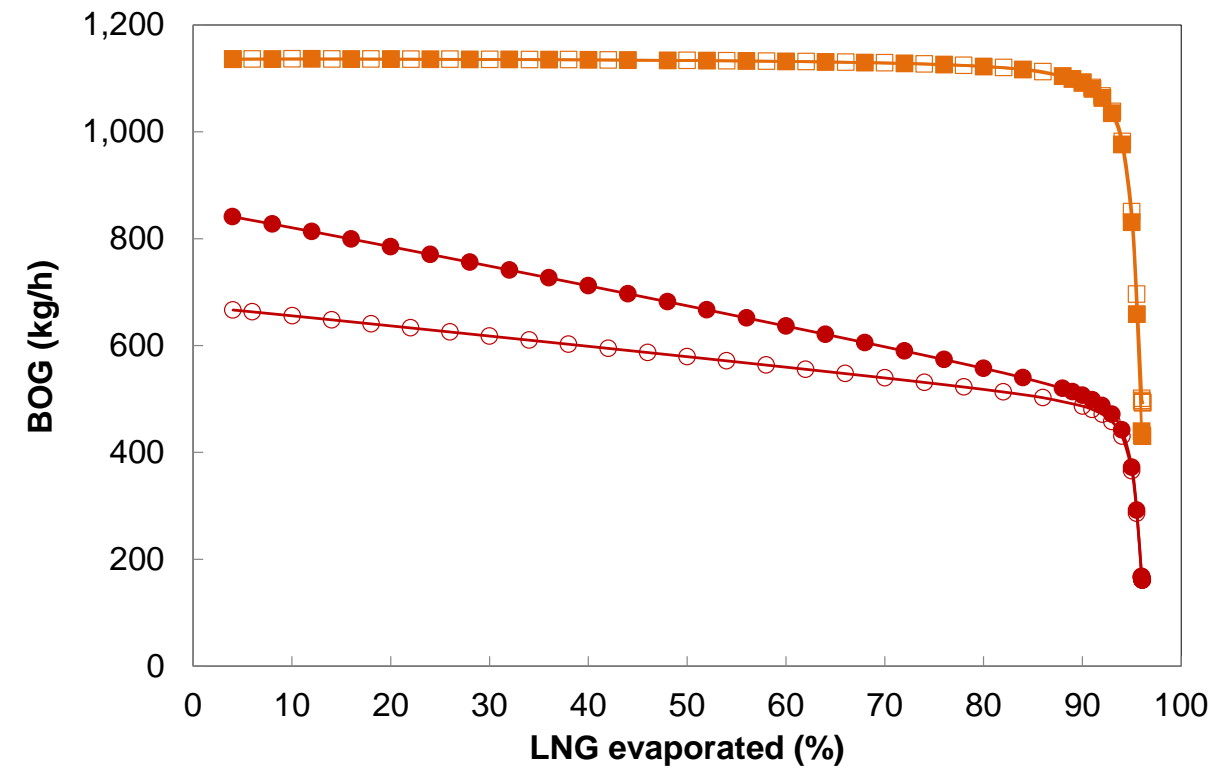

Figure 7 The variation of the BOG rate as a function of the amount of LNG evaporated (- $\bullet$-conduction model, $160,000 \mathrm{~m}^{3} ;-\bigcirc$ - conduction model, $80,000 \mathrm{~m}^{3}$; convection model, $160,000 \mathrm{~m}^{3} ;-\square$ - convection model, $80,000 \mathrm{~m}^{3}$ ) 
We observe that for the conduction model the initial BOG rate is initially lower as a result of lower wall surface area and it decreases at approximately the same rate as the level of LNG in the tank decreases. The difference in slope between the $160,000 \mathrm{~m}^{3}$ and $80,000 \mathrm{~m}^{3}$ can be ascribed to a larger heat influx from the bottom slab in the latter case. In the final stages we observe a rapid decrease in the BOG rate due to already discussed [16] LNG enrichment, as methane preferentially evaporates.

In this work we have examined two limiting scenarios of heat transfer from the vapour to the LNG. The current simulations illustrate that the conduction case leads to an observable temperature increase which is in line with the industrial evidence [17] showing that the vapour temperature in the tank is higher than the liquid (LNG) temperature. Similar industrial observations, seldom reported in the open literature, have been made for other cryogenic tanks containing oxygen and nitrogen and for tanks containing liquid ammonia. Furthermore, the fact that the weathering process is slow and that the temperature gradient in the vapour is positive further supports more conductive than convective heat transfer between the vapour and the LNG. Unfortunately, no reliable measurements of the vapour temperature in the industrial tanks are available in the literature to confirm the magnitude of the effect. Until such measurements become available the current hypothesis that the heat transfer is primarily by conduction will have to suffice. We have also performed a series of calculations [28] using the concept of the effective thermal conductivity to explore the intermediate stages of heat transfer between pure conduction and full convection. The results indicate that increasing the thermal conductivity by approximately two orders of magnitude replicates the convective scenario.

\subsection{Heavy LNG}

We have also performed simulations on the weathering of Heavy LNG. The results and observed trends are the same as those for light LNG, at least over the 52 week period of interest. This is not surprising as the early stages of vaporization of LNG are independent of the LNG composition, as long as $\mathrm{N}_{2}$ is not present. The vapour is essentially methane, the latent heat is constant and the boiling temperature of the remaining LNG hardly changes. As the vapour blanket above the Heavy LNG is made of methane, both the conduction and convection models provide the same heat influx as in the case of Light LNG. The temperature of the vapour phase above Heavy LNG increases to $122 \mathrm{~K}$ over the 52 week period, while the BOG rate drops to $828 \mathrm{~kg} / \mathrm{h}$ based on simulations performed using the conduction model. 


\subsection{Sensitivity to initial $N_{2}$ content}

Migliore et. al. [16] showed that the presence of nitrogen in LNG decreases the BOG markedly during the initial stages of weathering. Within this work the effect is re-examined further using the convection and conduction models. The analysis is performed by comparing an actual Light LNG to a number of hypothetical $\mathrm{N}_{2}$ enriched LNG mixtures of up to $4.0 \% \mathrm{~N}_{2}$ content (see Table 1 for the compositional variation), all weathering in $165,000 \mathrm{~m}^{3}$ standard containment tank initially filled with $160,000 \mathrm{~m}^{3}$ of LNG.

At the level of LNG thermophysical properties the presence of nitrogen manifests itself primarily in two ways. It reduces the boiling temperature of the LNG mixture and increases the direct differential molar latent heat required to boil an infinitesimal drop of LNG. Although they have opposite effects on the weathering rate, the previous work [16] has shown that the latter is dominant. Figure 8 illustrates the behaviour of the vapour and LNG temperature as a function of time for the conduction model for different initial nitrogen content. For the convection model the vapour temperature is less than one degree higher than the LNG temperature, in each case, and is not shown in Figure 8. We observe that the rate of increase of the difference between the vapour and LNG temperature is nearly independent of the nitrogen content.

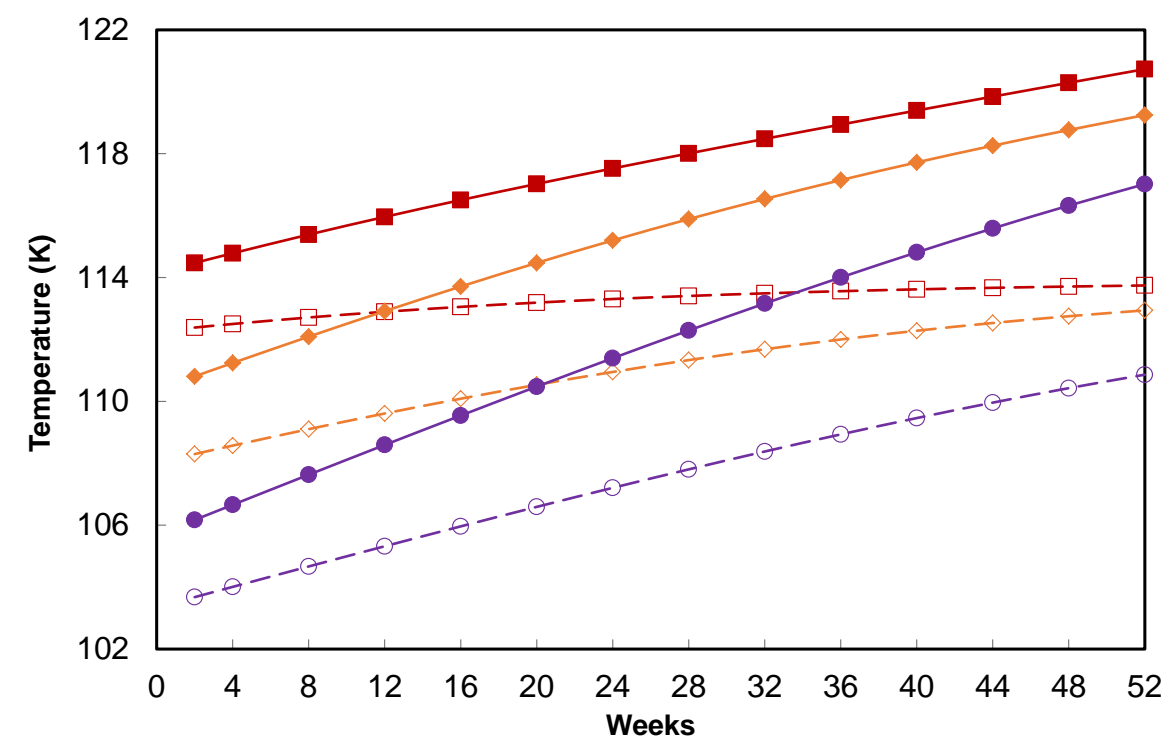

Figure 8 The variation of the vapour and LNG temperature during the weathering process: $\left(-\square-T_{V} 0.5 \% N_{2} ;-\square-T_{L N G} 0.5 \% N_{2} ;->-T_{V} 2.0 \% N_{2} ;-\diamond-T_{L N G} 2.0 \% N_{2} ;-\bullet-T_{V}\right.$ $4.0 \% \mathrm{~N}_{2} ;-\bigcirc-\mathrm{T}_{\text {LNG }} 4.0 \% \mathrm{~N}_{2} ;$ )

Figure 9 shows the BOG generation rate as a function of time for the $\mathrm{N}_{2}$ enriched LNG mixtures. 


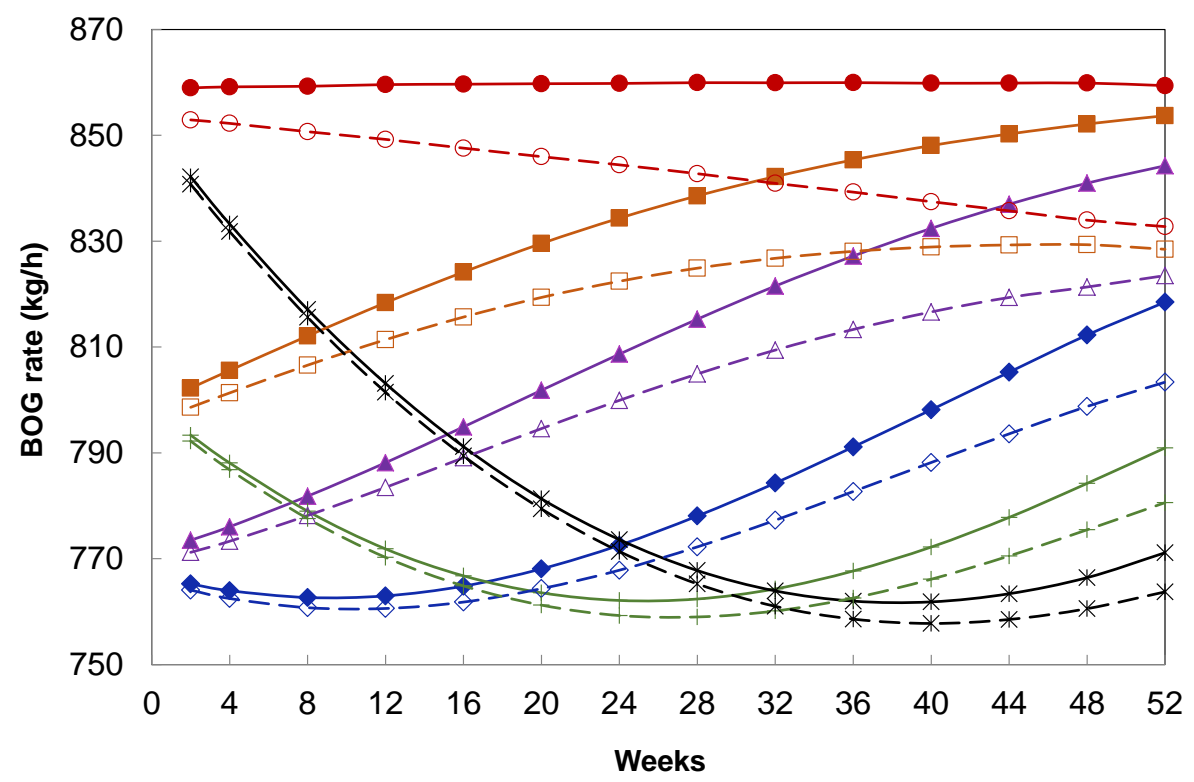

Figure 9 The variation of the BOG rate during the weathering process: convection model, solid line, full symbols (-๑- light LNG; - $0.5 \% \mathrm{~N}_{2} ;-\Delta-1.0 \% \mathrm{~N}_{2} ;->-1.5 \% \mathrm{~N}_{2}$; -*-3.0\% $\left.\mathrm{N}_{2} ; \quad-+-4.0 \% \mathrm{~N}_{2}\right)$; conduction model, dashed line, open symbols $(-\mathrm{O}$ light LNG; $-\square-0.5 \% \mathrm{~N}_{2} ;-\triangle-1.0 \% \mathrm{~N}_{2} ;-\diamond-1.5 \% \mathrm{~N}_{2} ;-*-3.0 \% \mathrm{~N}_{2} ;-+-4.0 \% \mathrm{~N}_{2}$ )

We observe that the initial nitrogen content of the LNG has a significant influence on the BOG rate. For LNG with low nitrogen content $\left(\mathrm{N}_{2}<1 \%\right)$ both the conduction and the convection model demonstrate that the initial BOG rate will decrease significantly with an increase in the nitrogen content. This is despite the higher temperature driving force, due to the decrease in the LNG boiling temperature, see Figure 8, which results in higher heat influx. The determining factor, as reported previously [16], is the increase in the direct differential molar latent heat with increase in nitrogen content. Once the weathering process starts, nitrogen will preferentially evaporate and the direct differential molar latent heat will decrease, thus in the later stages of the weathering less heat is needed to vaporize the LNG. Although the heat flux entering the LNG from the surroundings also decreases, it is not sufficient to compensate for the decrease in the latent heat and the BOG rate will increase, as illustrated by the convection model in Figure 9. For LNG with a higher nitrogen content $\left(\mathrm{N}_{2}>1 \%\right)$ one would observe exactly the same behaviour if the weathering is analysed in terms of molar BOG. Hence, for the convection model, on the molar basis the initial BOG rate decreases with nitrogen content and increases during the weathering process. However, when we examine the weathering process in terms of the BOG rate expressed on the mass basis, see Figure 9, we observe a different trend for LNG with high nitrogen content. The initial BOG rate is higher and it decreases with weathering, see Figure 9. The observed change in behaviour can be primarily attributed to the higher molecular weight of the generated vapour [16] as a result of preferential evaporation of nitrogen in the initial stages of weathering. The change in the differential indirect latent heat plays a secondary role in the process. 
As the weathering proceeds, the LNG becomes light in nitrogen and the BOG rate tends to be similar irrespective of the initial nitrogen content. For the simulation period of one year, used in this study, we observe this behaviour for LNG with less than $1.5 \%$ of nitrogen. The $\mathrm{N}_{2}$-rich LNG would take more than a year to reach this stage. We also observe that the difference in the predicted BOG rate between the convection and conduction models is smaller for LNG with higher initial nitrogen content. This, at first, surprising result is simply a consequence of lower molar BOG rates that $\mathrm{N}_{2}$-rich LNG experiences at all stages of the weathering process. Thus, after a given time less $\mathrm{N}_{2}$-rich LNG would have evaporated compared with LNG with low nitrogen content, leading to a much smaller reduction in the wet area. As we have seen in section 4.1 the decrease in the wet area is the primary cause of lower BOG rate for the conduction model.

As there are a number of competing factors that influence the mass BOG rate, it is interesting to observe how the BOG rate varies with the initial nitrogen content. Figure 10 shows the variation of the BOG rate predicted by the conduction model for a specific weathering duration, as a function of the initial amount of nitrogen. We observe that for the early stages of weathering the minimum mass BOG rate is observed for LNG with approximately initially $1.5 \%$ nitrogen, thus confirming the previous results [16] obtained with the isothermal model.

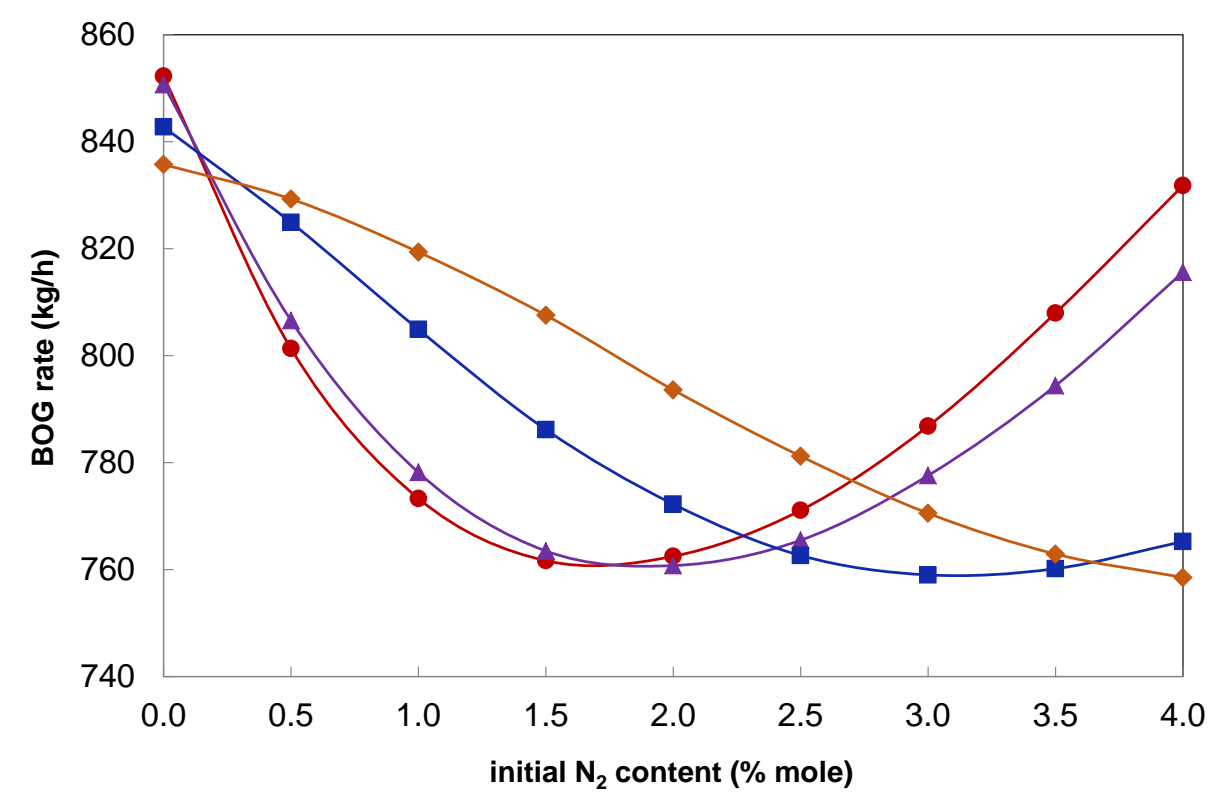

Figure 10 The variation of the BOG rate as a function of different initial nitrogen content after weathering for: - $\bullet-4$ weeks; - $\Delta$ - 8 weeks; - -28 weeks; - $>-44$ weeks.

For longer weathering durations the minimum BOG rate occurs for the LNG that initially had a higher nitrogen content. Overall, all the mixtures that start with the initial nitrogen content higher 
than $1.5 \%$ exhibit a minimum BOG rate of approximately $750-760 \mathrm{~kg} / \mathrm{h}$ when the mole fraction of nitrogen in the LNG phase reaches approximately $1.45-1.55 \%$. This is the result of interplay between the boiling temperature, direct differential molar latent heat and molecular weight of the vapour.

\section{Summary and Conclusions}

A stand-alone model for rigorous prediction of LNG weathering in containment storage tanks, typically used in regasification terminals, has been developed. The main advancement on the current generation of models is that the vapour blanket inside the containment tank is not assumed to be at the same temperature as the stored LNG. This was achieved by decoupling the overall heat influx from the surroundings, into the heat flux entering vapour phase and heat flux entering the liquid phase. As the latter will primarily lead to weathering, while the former will lead to an increase in temperature, the vapour temperature is always going to be equal or greater than the LNG boiling temperature. The model incorporates the resulting heat transfer from the vapour phase by considering two limiting scenarios, namely conduction and convection.

The results indicate that if the heat transfer between the vapour phase and LNG is by conduction only the vapour temperature will increase throughout the weathering process. For the storage tank considered in this work that has weathered for a year the vapour temperature will be approximately $8{ }^{\circ} \mathrm{C}$ higher than the boiling temperature of LNG. The lack of efficient heat transfer between the vapour and liquid phase will result in a decrease in BOG as weathering progresses. Compared with the isothermal case, where it is assumed that all the heat ingress goes into weathering the LNG, the BOG will drop by as much as $25 \%$ under certain scenarios. If one considers the other limiting possibility and assumes that the heat transfer between the vapour phase and LNG is by convection then the process is much more efficient, the vapour temperature increases by less than a degree and BOG is similar to that obtained in the isothermal case.

There are currently no reliable measurements of the vapour temperature in the working LNG containment tanks that would allow for a clear distinction between the two limiting heat transfer models. However, the scant industrial evidence and dynamics of weathering favour more heat transfer by conduction. If this is the case then the present model offers a more cost effective approach to industry as the currently available models assume isothermal conditions within the containment tank and attribute all the heat influx to weathering. This results in higher BOG rates and more conservative practices with an additional cost impact both at the design and operation stage. 
The simulations indicate that the amount of nitrogen in LNG has a significant effect on BOG in the initial stages of weathering. The presence of nitrogen decreases the boiling point temperature of LNG, increases the direct molar differential latent heat and increases the molecular weight of generated vapour, due to preferential evaporation of nitrogen. The interplay between these effects produces BOG rates that are in general very different to those for weathering of LNG with no nitrogen. The current results indicate that the minimum BOG rate is observed for LNG containing approximately $1.4-1.5 \%$ of nitrogen. The implications for industry are significant as the dynamics of initial weathering are different in the presence of nitrogen and, as the initial BOG generated is very rich in nitrogen, the resulting gas mixture falls out of spec by any regulatory measures and cannot be fed directly into the natural gas grid. 


\section{REFERENCES}

[1] International Energy Agency. World Energy Outlook: Are we entering a golden age of gas? Paris: International Energy Agency; 2011.

[2] BP Statistical Review of World Energy. London: BP; 2016.

[3] Migliore C. Natural Gas Conditioning and Processing. In: Riazi MR, Eser S, Agrawal SS, Peña Díez, JL, editors. Petroleum Refining and Natural Gas Processing. USA: ASTM International; 2013, p249-286. https://dx.doi.org/10.1520/MNL5820131212311

[4] BP Energy Outlook 2035. London: BP; 2015.

[5] Lowell D, Wang H, Lutsey $\mathrm{N}$. Assessment of the fuel cycle impact of liquefied natural gas as used in international shipping. The International Council on Clean Transportation (ICCT), White paper, USA; 2013.

[6] Rosenstiel DP. LNG in Germany: Liquefied natural gas and renewable methane in heavyduty road transport. Berlin: German Energy Agency (DENA); 2014

[7] Churchill SW. Heat leakage and wall temperature profiles for above-ground lowtemperature storage tanks. Chem Eng Prog S Ser 1962;58(11):55-60.

[8] Neill DT, Hashemi HT, Sliepcevich CM. Boil-off rates and wall temperatures in above ground LNG storage tanks. Adv Cryogenic Heat Transfer, Chem Eng Prog Symp Ser 1968;64(87):111-119.

[9] Kountz KJ. Weathering of LNG in on-board storage tanks. Institute of Gas Technology IGT project report 32034-02; 1999.

[10] Dimopoulos GG, Frangopoulos CA. A dynamic model for liquefied natural gas evaporation during marine transportation. Int J Thermodyn 2008;11(3);123-131.

[11] Miana M, Del Hoyo R, Rodrigálvarez V, Valdés JR, Llorens R. Calculation models for prediction of liquefied natural gas (LNG) ageing during ship transportation. Appl Energy 2010;87(5);1687-1700. https://dx.doi.org/10.1016/j.apenergy.2009.10.023

[12] Miana M, Del Hoyo R, Rodrigálvarez V. Comparison of evaporation rate and heat flow models for prediction of liquefied natural gas (LNG) ageing during ship transportation. Fuel 2016;177;87-106. http://dx.doi.org/10.1016/j.fuel.2016.02.070 
[13] Chen QS, Wegrzyn J, Prasad V. Analysis of temperature and pressure changes in liquefied natural gas (LNG) cryogenic tanks. Cryogenics 2004;44(10);701-709. http://dx.doi.org/10.1016/j.cryogenics.2004.03.020

[14] Adom E, Islam SZ, Ji X. Modelling of boil-off gas in LNG tanks: A case study. Int J Eng Tech 2010;2(4);292-296.

[15] Pellegrini LA, Moioli S, Brignoli F, Bellini C. LNG Technology: The weathering in aboveground storage tanks. Ind Eng Chem Res 2014;53(10);3931-3937.

https://dx.doi.org/10.1021/ie404128d

[16] Migliore C, Tubilleja C, Vesovic V. Weathering prediction model for stored liquefied natural gas (LNG). J Nat Gas Sci Eng 2015;26;570-580.

https://dx.doi.org/10.1016/j.jngse.2015.06.056

[17] Operations supervisor, LNG regasification facility. Personal communication, 28th March 2014.

[18] Haque MA, Richardson SM, Saville G. Blowdown of pressure vessels. I. Computer model. Proc Safety Envir Protect 1992;70; 3-9.

[19] Overa SJ, Stange E, Salater P. Determination of temperatures and flare rates during depressurization and fire, Proceedings of 72nd Gas Processors Association Annual Convention, 15-16 March, San Antonio, TX, USA; 1993,. p. 235-247.

[20] Mahgerefteh $\mathrm{H}$, Wong SMA. A numerical blowdown simulation incorporating cubic equations of state. Comp Chem Eng 1999;23(9);1309-1317.

[21] Danesh A. PVT and phase behaviour of petroleum reservoir fluids. The Netherlands: Elsevier Science; 1998.

[22] Groupe International des Importateurs de Gaz Naturel Liquéfié - GIIGNL. LNG custody transfer handbook, $3^{\text {rd }}$ edition, Paris; 2010.

[23] Conrado C, Vesovic $V$. The influence of chemical composition on vaporisation of LNG and LPG on unconfined water surfaces. Chem Eng Sci 2000;55;4549-4562. http://dx.doi.org/10.1016/S0009-2509(00)00110-X

[24] Zubari A. Modelling LNG spill on water, PhD thesis, Imperial College London; 2011,

[25] Carlshaw HS, Jaeger JC. Conduction of heat in solids. $2^{\text {nd }}$ edition, Oxford: Clarendon Press; 1959.

[26] Kozanoglu B, Rubio F. The Characteristic Length on Natural Convection from a Horizontal Heated Plate Facing Downwards. Therm Sci 2014;18(2);555-561. 
[27] Corcione M. Heat transfer correlations for free convection from upward-facing horizontal rectangular surfaces. WSEAS Trans Heat \& Mass Trans 2007;3(2);48-60.

[28] Migliore C, Salehi A, Vesovic V. Weathering of stored Liquefied Natural Gas (LNG), Proceedings of 10th International Conference on Thermal Engineering: Theory and Applications, 26-28 February, Muscat, Oman; 2017.

\section{Abbreviations}

$\begin{array}{ll}\text { BOG } & \text { Boil-off Gas } \\ \text { EOS } & \text { Equation of State } \\ \text { LNG } & \text { Liquefied Natural Gas } \\ \text { PR-EOS } & \text { Peng Robinson Equation of State }\end{array}$

